\title{
Effects of Extraction Process Parameters on the Quality Characteristics of Parinari Polyandra B. Seed Oil
}

\author{
T. E. Odetoye ${ }^{1 *}$, T. J. Afolabi ${ }^{2}$, K. R. Onifade ${ }^{3}$ \\ ${ }^{1}$ Department of Chemical Engineering, University of Ilorin, Ilorin, Kwara State, Nigeria. \\ ${ }^{2}$ Department of Chemical Engineering, Ladoke Akintola University of Technology, Ogbomoso, Nigeria. \\ ${ }^{3}$ Department of Chemical Engineering, Federal University of Technology, Minna, Nigeria.
}

\begin{abstract}
Extraction process parameters can influence the quality of oil obtained from seeds during extraction process. The effect of extraction process parameters on the quality of parinari seed oil, a potential renewable industrial raw material, is yet to be reported. This research was aimed at investigating the effects of some extraction process parameters on some quality characteristics of parinari oil (acid, iodine and saponification values). This work reports for the first time the effects of extraction process parameters on the properties of parinari seed oil. The parinari seeds were harvested and oil was obtained from the seeds by solvent extraction method based on the experimental design. The experimental design followed central composite design (CCD). Effects of extraction parameters on the quality characteristics were investigated. The study parameters were time $(2-6 \mathrm{~h})$, temperature $\left(60-70{ }^{\circ} \mathrm{C}\right)$, solid- solvent ratio $\left(0.03-0.08 \mathrm{~g} / \mathrm{cm}^{3}\right)$ and solvent types (n-hexane and petroleum ether). The responses were acid, saponification and iodine values. The results indicated that time and temperature significantly influenced the physicochemical properties of parinari oil. Response Surface Methodology (RSM) based analysis of variance indicated that the models obtained were all significant $(\mathrm{p}<0.0001)$. The set of conditions for the optimal quality was obtained at temperature $\left(60{ }^{\circ} \mathrm{C}\right)$, time $(2 \mathrm{~h})$, solid to solvent ratio $\left(0.07 \mathrm{~g} / \mathrm{cm}^{3}\right)$ and $\mathrm{n}$-hexane solvent with $89.7 \%$ desirability. The effects of the extraction process parameters on parinari oil quality were obtained. The information provided from this work will be useful for potential scaling up of the parinari oil extraction process.
\end{abstract}

KEYWORDS: Parinari seed oil, quality, acid value, iodine value, extraction, response surface methodology.

[Received January 26, 2016; Revised October, 17, 2016; Accepted November 27, 2016]

\section{INTRODUCTION}

Vegetable oils are lipids that are extracted from plants seeds, fruits or seedlings (Zielinska et al., 2014). Solvent extraction is a commonly used separation method for obtaining industrial vegetable oil from oil-bearing plant parts (Islam et $a l ., 2015)$. Extraction process parameters such as temperature, time and agitation are important parameters which have significant effects on the quality (Lee et al., 2013) and spoilage (Orji and Mbata, 2008) of seed oils. Hence, various researches have been tailored towards the determination of the effects of extraction parameters on the quality of various seed oil extracted (Tasan et al., 2011; Ikya et al., al, 2013; Myung-Hee et al., 2013; Samuagam et al., 2013; Lee et al., 2013). Several reports have shown that the quality of various oil were significantly affected by the extraction parameters, these include sunflower oil (Tasan et al., 2011), olive oil (Giovacchino et al., 1994), palm oil (Ngando-Ebongue et al., 2013), coconut oil (Sereviratne \& Dissanayake, 2005), Jatropha oil (Akowuah et al., 2012) and ginseng seed oil (Myung-Hee et al., 2013). However, some workers have reported that the technique used for oil processing does not markedly alter the quality of argan oil. (Tariback et al., 2013).

*Corresponding author's e-mail address: odetoye.te@unilorin.edu.ng
Parinari polyandra Benth (or Maranthes polyandra) plant is found in West Africa, extending from Mali to Sudan (Keay, 1989). The plant is known as 'abo idofin' and 'gwanja kwosa' in Yoruba and Hausa languages in Nigeria (Abolaji et al., 2007). The parinari fruits (Figure 1) contains a relatively oil rich kernel which yields up to 64\% oil (Afolabi et al., 2014). Our earlier works indicated that parinari seed oil is a potential non-edible oil which can be utilized as a replacement for edible soya oil used in the production of alkyd polymer resin, a main raw material in the paints industries (Odetoye et al., 2013; Odetoye et al., 2014). Other earlier works on parinari oil include investigation of the effects of some extraction parameters on the oil yield (Afolabi et al., 2015) and variation of parinari oil characteristics with season of harvest (Motojesi et al.,2011).

The quality of oil is of commercial interest and quality is indicated by the physico-chemical properties of oil which include acid, iodine, peroxide, hydroxyl and saponification values. The acid value is an important quality characteristic in the specification of fats and oils because acid value indicates the level of free fatty acid present in the oil (Liauw, 2008). A relatively lower acid value implies better storage and shell life of the oil. Acid value is regarded as the number of milligrams of potassium hydroxide necessary to neutralize the free acid in doi: http://dx.doi.org/10.4314/njtd.v13i2.1 
one gram of oil. Iodine value is a measure of the level of unsaturation of fats and oils, and is expressed in terms of the weight of iodine absorbed per weight of the sample. Iodine value is an indicator for double bonds in the fatty acid chain. Iodine value is also indicative of the long term stability properties of the oil, a factor to be considered in storage of oil. Iodine value is measured as the number of grams of iodine absorbed by 100 grams of oil sample (AOAC, 2006; Ikya et al., 2013).

Higher iodine values are indicative of higher degree of unsaturation, which contributes to the functionality and reactivity of the oil (Murphy, 2012). The double bonds and the carboxylic ends provide sites for crucial industrial reactions in the development of building blocks for polymers as the reaction are carried out on the double bonds of the unsaturated glycerides. These reactions include autoxidation, dimerization, epoxy ring-opening and ozonolysis useful in the production of polymers, paints, inks, resins, coatings and other oil-based chemicals (Ogunniyi, 2006). However, lower iodine values are desirable in oils meant for food uses and biodiesel production.

There is a need to determine the effect of extraction conditions on the quality of the oil obtained from parinari seeds, to provide necessary information towards the establishment of parinari oil as a new industrial feedstock. Little work has been done on parinari oil, the variation in lipid composition of the seed oil with time of harvest had been reported (Motojesi et al., 2011). In our earlier work (Afolabi et al., 2014), the optimization of extraction process of parinari oil for optimal yield was reported. However, in this work, we report the effect of extraction parameters on the quality characteristics of oil obtained from parinari seed by solvent extraction.

\section{MAterials AND Methodology}

\section{A. Sample Preparation}

Ripe fruits of Parinari polyandra fruits as shown in Figure 1 were picked from trees at different locations in Ilorin, Kwara State, Nigeria in April, 2014 and identified at the herbarium of the Department of Biology, University of Ilorin, Nigeria. The fruits were manually broken into halves to release the whitish seed kernels containing the oil. The seeds were cleaned and air-dried at room temperature after which size reduction was achieved by pounding the seeds with laboratory mortar and pestle to increase the contact surface for extraction. A particle size of approximately $2 \mathrm{~mm}$ was obtained after passing through a set of standard laboratory mesh sieve. All reagents were of analytical grade and were used as purchased from BDH Chemicals, Poole, England.

Table 1: Experimental Design Summary.

\section{B. Design Experiment}

The design of experiment was based on central composite design (CCD) using Response surface methodology (RSM) function of the commercial package, Design Expert version 6.0.8. (Stat-Ease Inc, Minneapolis, U.S.A.). The experimental process variables time $\mathrm{t}(\mathrm{hr})$, temperature $\mathrm{T}\left({ }^{\circ} \mathrm{C}\right)$ and solid/solvent ratio $\mathrm{V}(\mathrm{g} / \mathrm{cm} 3)$ were transformed respectively to the coded variables A, B, and C thus;

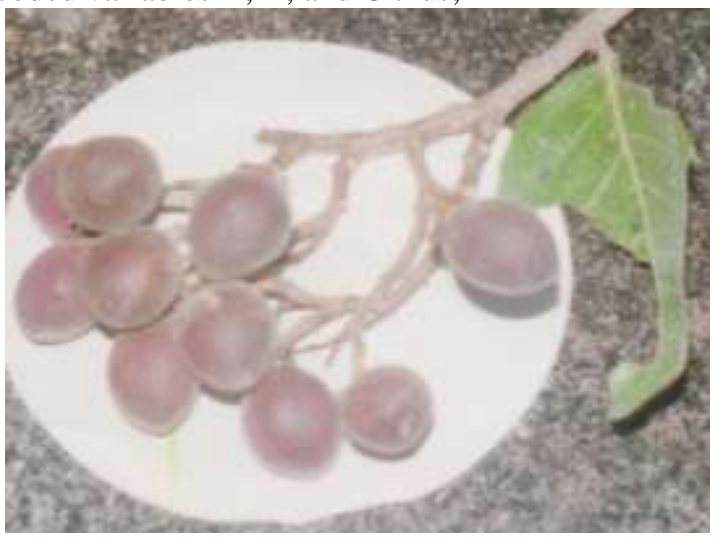

Figure 1: Parinari fruits, leaf and kernel.

$$
\begin{aligned}
& \mathrm{A}=(\mathrm{t}-4) / 2 \\
& \mathrm{~B}=(\mathrm{T}-65) / 5 \\
& \mathrm{C}=(\mathrm{V}-0.05) / 0.025
\end{aligned}
$$

Based on preliminary studies (Afolabi et al., 2014), a five level, four-factor design was employed in this study requiring 40 experiments. The summary of the experimental design is as presented in Table 1. The categorical factor; solvent type, was coded as D.

\section{Sample Extraction}

Solvent extraction method was used to study the effect of extraction conditions on the quality characteristics of parinari oil. The predicted 40 extraction experiments were conducted using a $250 \mathrm{~cm} 3$ capacity laboratory Sohxlet apparatus mounted on a regulated heating mantle by varying the parameters temperature, time, solid-solvent ratio and solvent types according to the experimental design (Table 1).

\section{Determination of Effects of Parameters on Oil Quality}

Acid values, and iodine values were determined according to AOCS methods (Firestone, 1996). Saponification values were determined according to AOAC (2006) Official method methods for the 40 different samples.

\section{E. Statistical Analysis and Optimization}

\begin{tabular}{|c|c|c|c|c|c|c|c|c|}
\hline \multirow[t]{2}{*}{ Factor } & \multirow[t]{2}{*}{ Name } & \multirow[t]{2}{*}{ Unit } & \multirow[t]{2}{*}{ Type } & \multicolumn{5}{|c|}{ Level } \\
\hline & & & & $-\alpha$ & -1 & 0 & 1 & $\alpha$ \\
\hline $\mathrm{A}$ & Time & hrs & Numeric & 0.64 & 2 & 4 & 6 & 7.36 \\
\hline B & Temperature & ${ }^{\circ} \mathrm{C}$ & Numeric & 56.21 & 60 & 65 & 70 & 73.36 \\
\hline $\mathrm{C}$ & Solid/solvent ratio & $\mathrm{g} / \mathrm{cm}^{3}$ & Numeric & 0.01 & 0.03 & 0.05 & 0.08 & 0.09 \\
\hline $\mathrm{D}$ & Solvent type & & Categorical & & n-Hexane & & Pet ether & \\
\hline
\end{tabular}

In the present study, response surface methodology was employed to obtain the optimal extraction condition giving oil 
of optimal quality within the experimental domain. The optimum oil quality condition was achieved by setting optimization goals of minimizing the acid value, maximizing iodine value and minimizing the saponification value within the range of values obtained. Design Expert 6.0.8. tool was also employed to achieve model fitting and statistical analyses.

\section{RESULTS AND DISCUSSION}

\section{A. Effects of Independent Variables on Parinari Oil Quality Characteristics}

The response variables representing three oil quality characteristics (acid valueY1, iodine value Y2 and saponification value Y3) were all best fitted as quadratic model. All the models were significant with values of "Prob > $\mathrm{F}$ less than 0.05 .

\section{Acid value}

The statistical analysis for acid value response $\mathrm{Y} 1$, indicated that the main effects were due to the coded factors $\mathrm{B}$, $\mathrm{A} 2, \mathrm{D}, \mathrm{A}$, and $\mathrm{BD}$, corresponding to temperature, quadratic effect of time, solvent type and linear interaction effect between temperature and solvent type respectively. The coded factors $\mathrm{C}$ corresponding to solid solvent ratio did not have significant effect on the acid value. The relationship was represented by a reduced quadratic model as stated in eqn 4 .

$$
\begin{aligned}
\mathrm{Y}_{1}= & 4.92-0.04 \mathrm{~A}+1.02 \mathrm{~B}-0.12 \mathrm{D}-0.95 \mathrm{~A}^{2}-0.34 \mathrm{BD} \\
& \text { where } \mathrm{Y}_{1}=\text { Acid value }
\end{aligned}
$$

The summary of the analysis of variance (ANOVA) and the experimental and predicted acid values for response equation $\left(\mathrm{Y}_{1}\right)$ are as shown in Tables 2 and 3 . The predicted coefficient of determination (R2) and adjusted coefficient of determination (R2adj) for Parinari oil acid value response model were obtained as 0.8555 and 0.8342 respectively, indicating the regression model as acceptable. The Prob $>\mathrm{F}$ value of less than 0.0001 was significant. The normal probability plots of residuals obtained from parinari oil acid value response equation analysis is as shown in Figure 2.
The effects of extraction temperature and time on the acid value for both the $n$-hexane and petroleum ether solvents at 60 ${ }^{\circ} \mathrm{C}$ and $70^{\circ} \mathrm{C}$ followed the same trend as indicated in Figure 3. The acid value was found to increase with increasing extraction temperature while extraction time tends not to have appreciable effect on the acid value. Relatively higher values were obtained at the temperature of $70{ }^{\circ} \mathrm{C}$ compared to $60{ }^{\circ} \mathrm{C}$ for both $n$-hexane and petroleum ether solvents, however, the trend was more pronounced in petroleum ether. These results indicated that relatively lower temperatures are desirable to obtain lower acid values in parinari oil.

This trend in acid value agrees with the trend reported in Jatropha oil and neem oil extractions respectively (Akowuah, 2012; Adewoye \& Ogunleye, 2012). This relatively lower temperature requirement favoured a more economical process when considering heating costs among other costs for the solvent extraction process. In Figure 4, the 3D response surface plots clearly show the linear relationship of acid value with temperature and the effects of temperature on acid values. The same trends were observed when n-hexane or petroleum ether was used, indicating that solvent type did not have appreciable effect on the acid value of parinari oil. In essence, the plots indicates that the main linear effects were due to the coded terms B, A2, D corresponding to temperature, time and solvent type, indicating that temperature, time and solvent type were factors responsible for the acid value of parinari oil obtained during extraction.

\section{Iodine value}

The final quadratic equation, Iodine value, $\mathrm{Y}_{3}$ in terms of coded factors was given as in eqn 5 .

$$
\mathrm{Y}_{3}=166.12-0.48 \mathrm{~A}-3.04 \mathrm{~B}+0.59 \mathrm{~A}^{2}-0.33 \mathrm{~B}^{2}-0.68 \mathrm{AB}
$$

The test for the significance and adequacy of the model showed that the main effects were due to the coded term B, A2

Table 2: Analysis of Variance (ANOVA) table for Parinari oil acid value response.

\begin{tabular}{lcccll}
\hline Source & $\begin{array}{l}\text { Sum of } \\
\text { Squares }\end{array}$ & $\begin{array}{l}\text { Degree of } \\
\text { Freedom }\end{array}$ & $\begin{array}{l}\text { Mean } \\
\text { Square }\end{array}$ & F Value & Prob > F \\
\hline Model & 58.96 & 5 & 11.79 & 40.25 & $<0.0001$ significant \\
Residual & 9.96 & 34 & 6.10 & & \\
Total & 68.92 & 39 & & & \\
A & 0.044 & 1 & 0.044 & 0.15 & 0.6994 \\
B & 28.41 & 1 & 28.41 & 96.96 & $<0.0001$ \\
D & 0.59 & 1 & 0.59 & 2.02 & 0.1641 \\
A $^{2}$ & 26.68 & 1 & 26.68 & 91.05 & $<0.0001$ \\
BD & 0.067 & 1 & 0.067 & 0.011 & 0.9170 \\
Lack of Fit & 6.08 & 24 & 0.25 & 0.65 & 0.8123 not significant \\
Pure Error & 3.38 & 10 & 0.39 & & \\
Std. Dev. & 0.54 & R-Squared & & 0.8555 & \\
Mean & 4.27 & Adj R-Squared & & 0.8342 & \\
C.V. & 12.68 & Pred R-Squared & & 0.8034 & \\
PRESS & 13.55 & Adeq Precision & & 24.131 & \\
\hline
\end{tabular}


Table 3: Design layout for parinari oil extraction for coded, uncoded values and responses.

\begin{tabular}{|c|c|c|c|c|c|c|c|c|c|c|}
\hline \multirow{3}{*}{ Run } & \multicolumn{4}{|c|}{ Coded values } & \multicolumn{4}{|c|}{ Responses } & \multirow{2}{*}{\multicolumn{2}{|c|}{ Saponification value }} \\
\hline & $\overline{\mathbf{A}}$ & $\overline{\mathbf{B}}$ & $\bar{C}$ & $\bar{D}$ & Acid value & & odine va & & & \\
\hline & & & & & $\mathbf{E x}$ & Pr & $\mathbf{E x}$ & Pr & $\mathbf{E x}$ & Pr \\
\hline 1 & 1 & 1 & -1 & 1 & 5.48 & 5.17 & 162.09 & 162.18 & 250.30 & 248.40 \\
\hline 2 & -1 & 1 & -1 & -1 & 3.87 & 4.80 & 165.65 & 164.50 & 231.23 & 226.08 \\
\hline 3 & 0 & 1.68 & 0 & 1 & 6.75 & 7.09 & 162.21 & 160.07 & 252.12 & 252.24 \\
\hline 4 & -1 & 1 & 1 & 1 & 5.30 & 5.25 & 165.11 & 164.50 & 252.56 & 251.19 \\
\hline 5 & 0 & 0 & 0 & -1 & 4.94 & 5.04 & 167.99 & 166.12 & 254.81 & 251.78 \\
\hline 6 & -1 & -1 & 1 & 1 & 2.30 & 2.52 & 169.40 & 169.23 & 256.20 & 255.27 \\
\hline 7 & 0 & -1.68 & 0 & -1 & 3.61 & 3.90 & 170.18 & 170.29 & 251.98 & 254.45 \\
\hline 8 & 0 & 1.68 & 0 & -1 & 6.24 & 6.18 & 160.20 & 160.07 & 246.13 & 245.06 \\
\hline 9 & 0 & 0 & 0 & 1 & 5.25 & 4.80 & 165.21 & 166.12 & 252.12 & 253.59 \\
\hline 10 & 0 & 0 & 0 & -1 & 5.54 & 5.04 & 165.32 & 166.12 & 254.81 & 251.78 \\
\hline 11 & -1.68 & 0 & 0 & -1 & 2.10 & 2.21 & 170.10 & 168.61 & 226.12 & 227.08 \\
\hline 12 & -1 & -1 & 1 & -1 & 3.84 & 3.45 & 168.19 & 169.23 & 247.14 & 248.68 \\
\hline 13 & 1 & 1 & 1 & 1 & 5.10 & 5.17 & 162.75 & 162.18 & 243.14 & 242.57 \\
\hline 14 & 0 & 0 & 0 & 1 & 4.25 & 4.80 & 166.21 & 166.12 & 252.12 & 253.59 \\
\hline 15 & 1 & -1 & -1 & -1 & 3.25 & 3.37 & 170.19 & 169.23 & 251.21 & 252.07 \\
\hline 16 & 0 & -1.68 & 0 & 1 & 3.13 & 2.50 & 169.20 & 170.29 & 252.30 & 250.90 \\
\hline 17 & -1 & 1 & -1 & 1 & 5.41 & 5.25 & 163.82 & 164.50 & 242.50 & 245.57 \\
\hline 18 & 1 & -1 & 1 & -1 & 3.23 & 3.37 & 170.30 & 169.61 & 252.20 & 247.99 \\
\hline 19 & 0 & 0 & 0 & 1 & 4.50 & 4.01 & 166.30 & 166.12 & 256.00 & 253.59 \\
\hline 20 & 0 & 0 & 0 & 1 & 4.14 & 4.80 & 167.14 & 166.12 & 252.92 & 253.59 \\
\hline 21 & 0 & 0 & 0 & -1 & 4.94 & 5.04 & 165.32 & 166.12 & 244.81 & 251.78 \\
\hline 22 & 0 & 0 & -1.68 & 1 & 4.21 & 4.80 & 168.11 & 166.12 & 252.27 & 252.11 \\
\hline 23 & 0 & 0 & 1.68 & -1 & 5.42 & 5.04 & 165.32 & 166.12 & 252.45 & 251.59 \\
\hline 24 & 1.68 & 0 & 0 & 1 & 2.80 & 2.03 & 168.50 & 166.98 & 253.14 & 248.65 \\
\hline 25 & -1 & 1 & 1 & -1 & 6.10 & 4.80 & 160.65 & 164.50 & 234.40 & 238.22 \\
\hline 26 & 0 & 0 & 0 & -1 & 5.74 & 5.04 & 166.99 & 166.12 & 254.81 & 251.78 \\
\hline 27 & 1 & 1 & -1 & -1 & 4.56 & 4.72 & 160.12 & 162.18 & 250.15 & 251.36 \\
\hline 28 & 1 & -1 & 1 & 1 & 2.10 & 2.44 & 170.13 & 169.61 & 226.12 & 232.12 \\
\hline 29 & 1.68 & 0 & 0 & -1 & 2.10 & 2.41 & 165.31 & 166.98 & 248.15 & 247.76 \\
\hline 30 & 0 & 0 & -1.68 & -1 & 4.65 & 5.04 & 164.58 & 166.12 & 240.40 & 244.81 \\
\hline 31 & 0 & 0 & 0 & -1 & 4.94 & 5.04 & 165.32 & 166.12 & 254.81 & 251.78 \\
\hline 32 & 0 & 0 & 0 & 1 & 5.25 & 4.80 & 166.21 & 166.12 & 252.12 & 253.59 \\
\hline 33 & 1 & -1 & -1 & 1 & 2.20 & 2.44 & 169.11 & 169.61 & 246.12 & 242.72 \\
\hline 34 & 0 & 0 & 0 & -1 & 4.94 & 5.04 & 165.32 & 166.12 & 250.81 & 251.78 \\
\hline 35 & 0 & 0 & 1.68 & 1 & 4.26 & 4.80 & 167.32 & 166.12 & 251.20 & 247.92 \\
\hline 36 & -1 & -1 & -1 & 1 & 2.15 & 2.52 & 169.34 & 169.23 & 254.32 & 254.43 \\
\hline 37 & -1 & -1 & -1 & -1 & 3.53 & 3.45 & 170.15 & 169.23 & 243.35 & 241.32 \\
\hline 38 & 1 & 1 & 1 & -1 & 4.12 & 4.72 & 160.14 & 162.18 & 249.65 & 252.26 \\
\hline 39 & 0 & 0 & 0 & 1 & 6.25 & 4.80 & 166.21 & 166.12 & 252.12 & 253.59 \\
\hline 40 & -1.68 & 0 & 0 & 1 & 2.10 & 168.3 & 168.61 & 168.32 & 248.23 & 247.78 \\
\hline
\end{tabular}

$\mathrm{EX}=$ Experimental, $\mathrm{PR}=$ Predicted, $\mathrm{S}=$ saponification
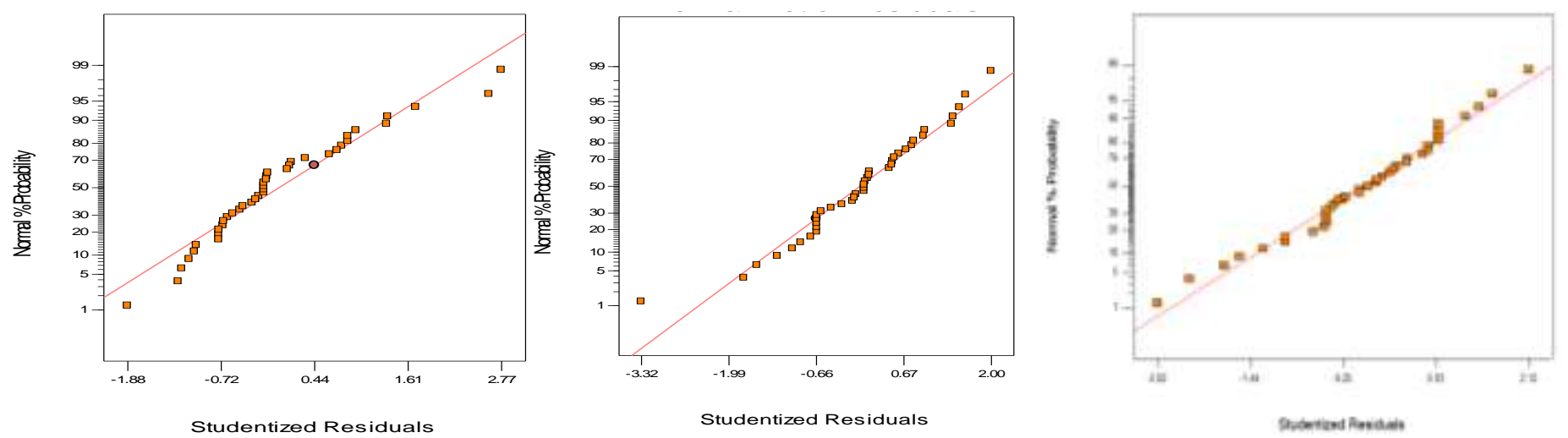

Figure 2. Normal probability plots of residuals for acid, iodine and saponification values obtained from parinari oil response data analyses. 

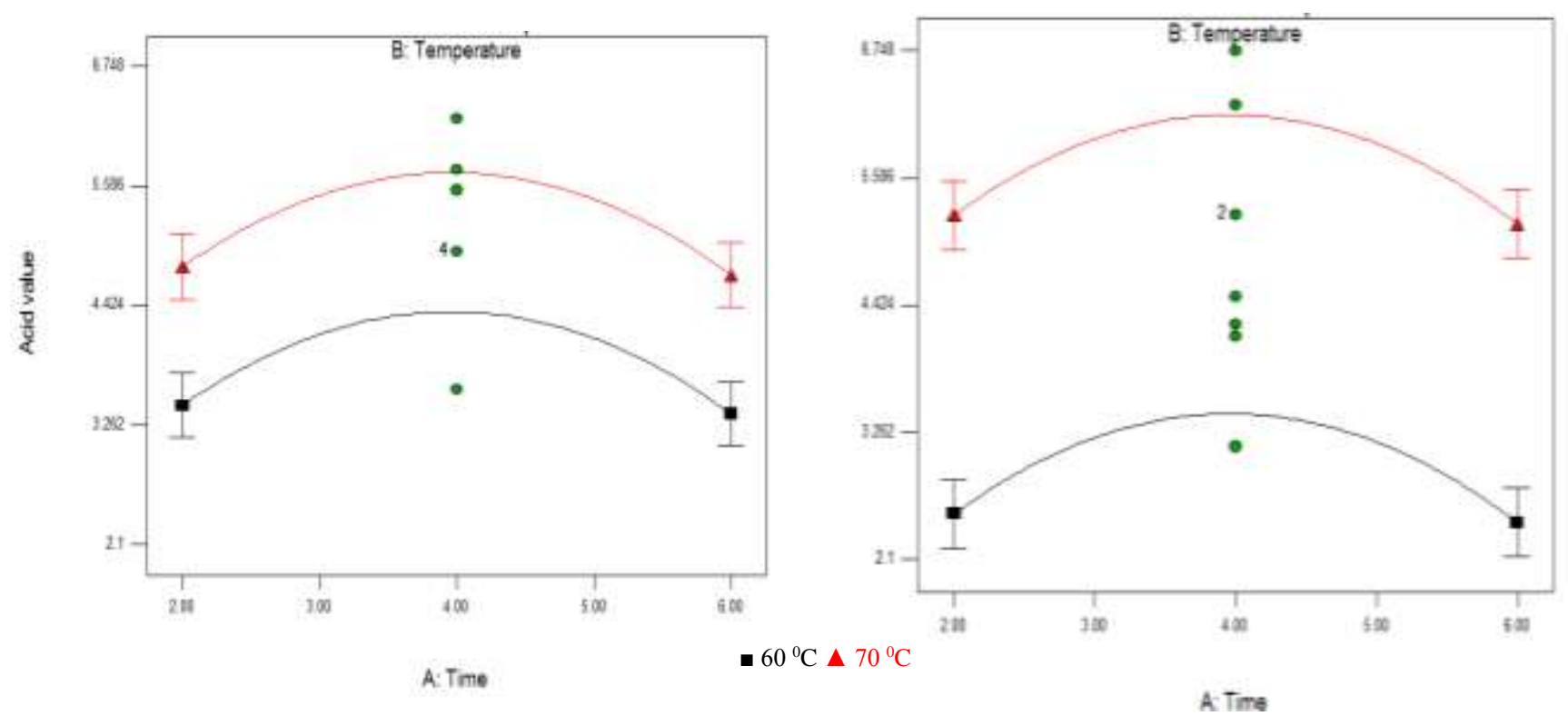

Figure 3: Acid value interaction graphs of temperature with time for $n$-hexane (A) and Petroleum ether (B) solvent types.
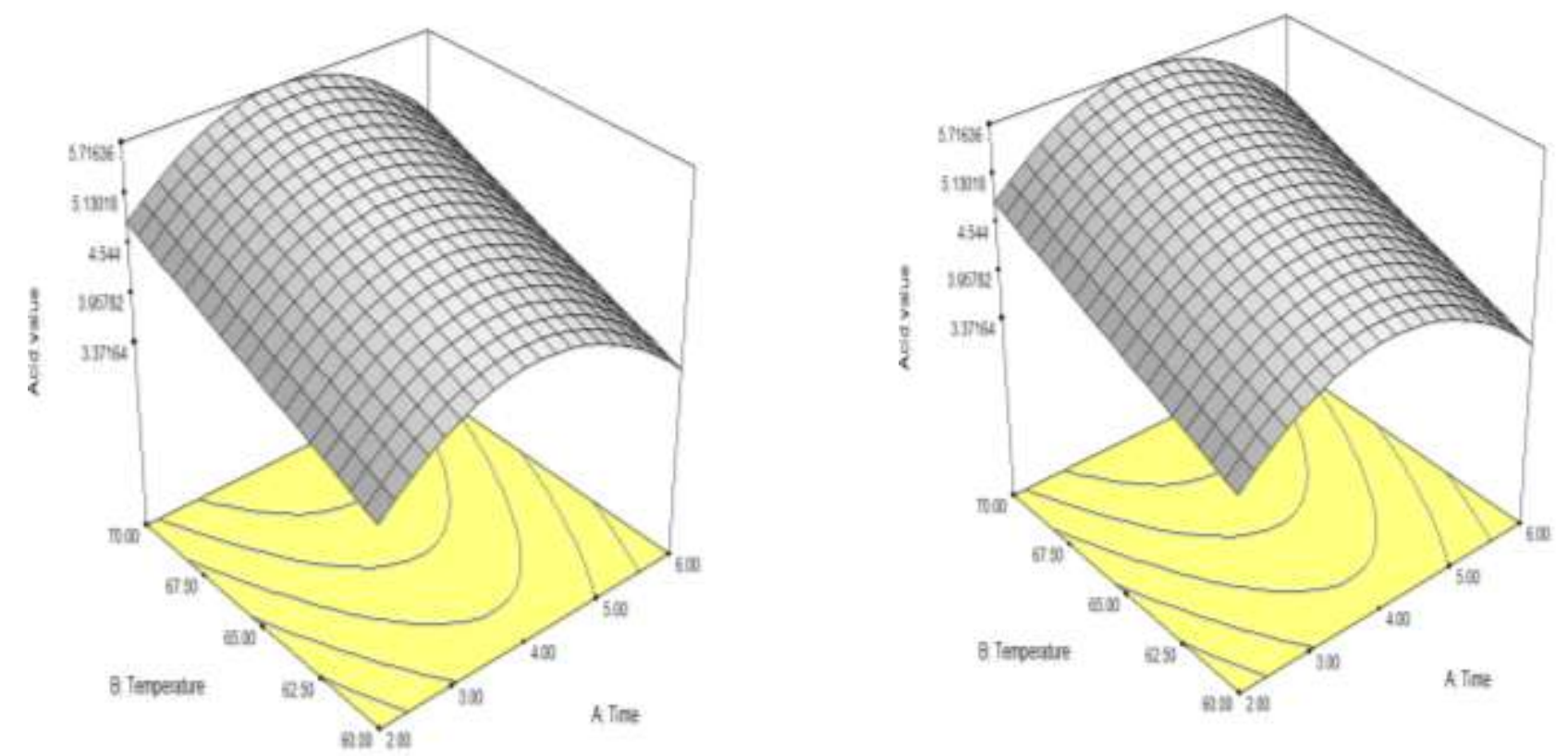

Figure 4: 4D response surface plots showing effect of temperature and time on acid value for $n$-hexane (A) and petroleum ether (B) solvent types.

and $\mathrm{AB}$, indicating that temperature was the most significant model term. The significance of the coded terms $\mathrm{A} 2$ and $\mathrm{AB}$ also indicated that the quadratic effect of time and interactive effect of time and temperature were important. The summary of the analysis of variance (ANOVA) obtained for equation Y3 is shown in Table 4 . The predicted and adjusted coefficients of determination (R2) and (R2adj) for Parinari oil iodine value response model equation were obtained as 0.8356 and 0.8114 respectively indicating the regression model as acceptable.

The ANOVA results of the regression quadratic model equation $\mathrm{Y}_{3}$ demonstrated that the model was highly significant, as it was evident from the calculated F-value (34.56) and a very low probability value (0.0001). The R2 value of 0.7564 is in fairly in agreement with the R2adj value of 0.8114 . The normal probability plot of residuals for data analysis obtained for parinari oil iodine values is shown in Figure 2. Figure 5 shows the interaction graph of temperature $\left(60{ }^{\circ} \mathrm{C}, 70^{\circ} \mathrm{C}\right)$ with time for $\mathrm{n}$-hexane and petroleum ether solvents while Figure 6 shows the effects of extraction parameters on iodine values. Temperature had a negative effect on iodine values when either of the solvent was used as indicated in the interaction graphs and response surface plots.

The iodine value was found to increase slightly with increasing extraction temperature and time. Extraction temperature tends to have more effects on the iodine value compared to time. However, solid-solvent ratio and solvent 
Table 4: Analysis of Variance (ANOVA) table for Parinari oil extraction iodine value response model $Y_{3}$.

\begin{tabular}{|c|c|c|c|c|c|}
\hline Source & $\begin{array}{l}\text { Sum of } \\
\text { Squares }\end{array}$ & $\begin{array}{l}\text { Degree of } \\
\text { Freedom }\end{array}$ & $\begin{array}{c}\text { Mean } \\
\text { Square } \\
\end{array}$ & F Value & Prob $>$ F \\
\hline Model & 280.37 & 5 & 56.07 & 34.56 & $<0.0001$ significant \\
\hline Residual & 55.17 & 34 & 5.78 & & \\
\hline Total & 415.63 & 39 & & & \\
\hline A & 6.39 & 1 & 6.39 & 3.94 & 0.0554 \\
\hline B & 252.16 & 1 & 252.16 & 155.4 & $<0.0001$ \\
\hline $\mathrm{A}^{2}$ & 10.14 & 1 & 10.14 & 6.25 & 0.0174 \\
\hline $\mathrm{B}^{2}$ & 3.23 & 1 & 3.23 & 1.99 & 0.1671 \\
\hline $\mathrm{AB}$ & 7.30 & 1 & 7.30 & 4.50 & 0.0413 \\
\hline Lack of Fit & 46.50 & 24 & 1.94 & 2.23 & 0.0930 not significant \\
\hline Pure Error & 8.67 & 10 & 8.67 & & \\
\hline Std. Dev. & 2.41 & & R-Squared & 0.8356 & \\
\hline Mean & 166.03 & & Adj R-Squared & 0.8114 & \\
\hline C.V. & 1.45 & & Pred R-Squared & 0.7564 & \\
\hline PRESS & 247.12 & & Adeq Precision & 20.715 & \\
\hline
\end{tabular}
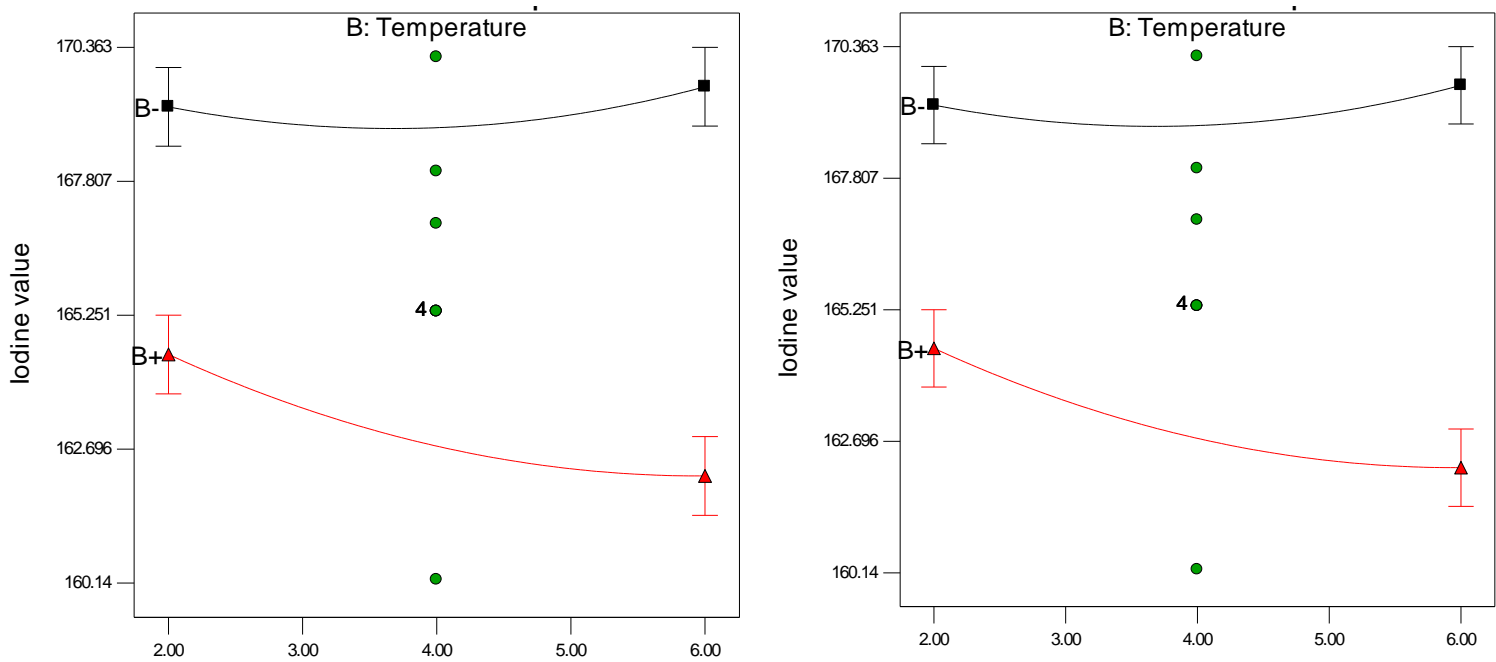
A: Time
- $60{ }^{\circ} \mathrm{C} \Delta 70{ }^{\circ} \mathrm{C}$
A: Time

Figure 5: Iodine value interaction graphs of temperature with time for $n-(A)$ and Petroleum ether (B) solvents.
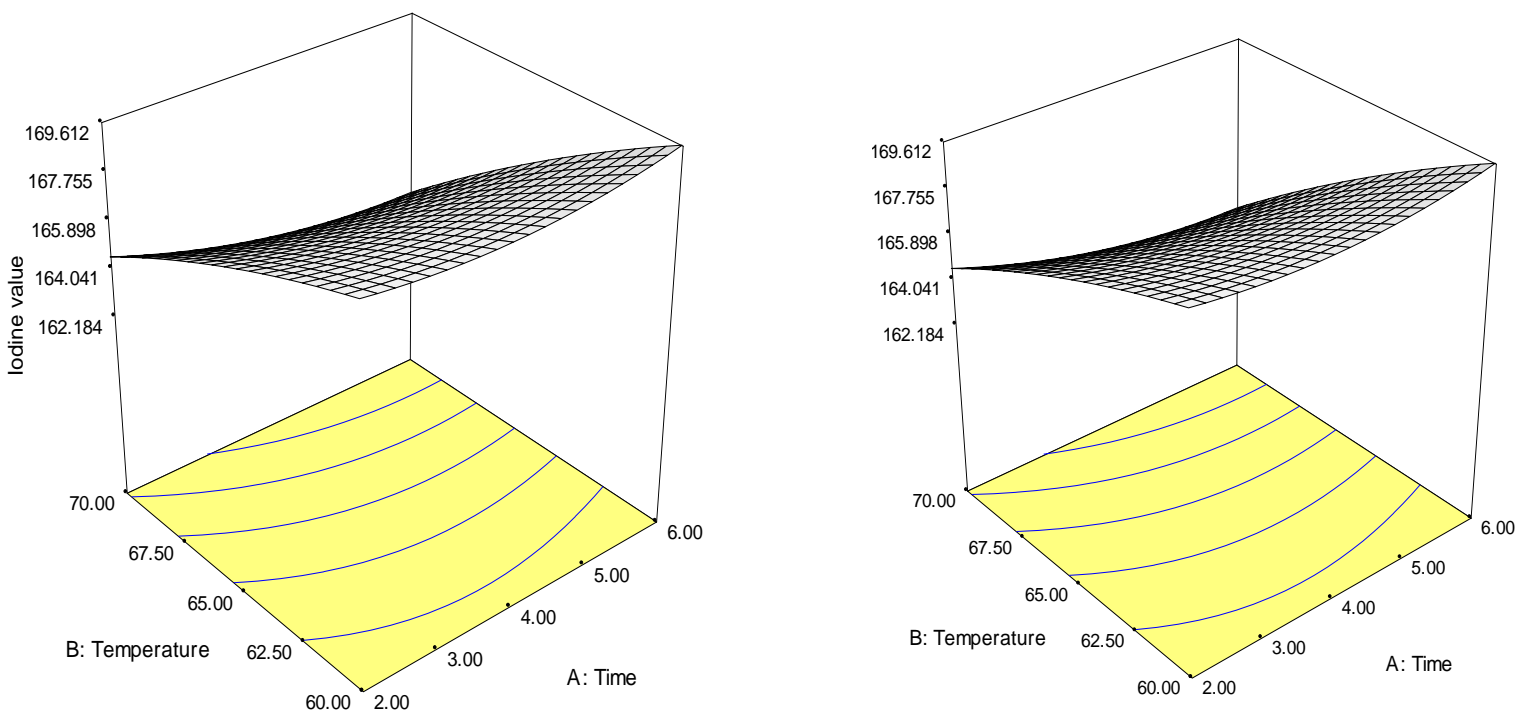

Figure 6: Effect of temperature and time on iodine value for $n$ - hexane solvent and pet ether solvent type. 
type did not have a significant effect on iodine value. Relatively lower temperatures and short extraction times tend to favour obtaining relatively high iodine value being an important property when considering the industrial utilization of the oil for reactions that depends on the methylenic bonds of the fatty acid chain e.g. hydrogenation, epoxidation, polyesterification (Murphy, 2012). Also, vegetable oils that have iodine values within the range obtained for parinari oil can be classified as drying oil.

Drying oils are important in the production of binders, resins and surface coatings in the paints industry (Murphy, 2012; Odetoye et al., 2013). However, high iodine values are generally undesirable in oils which are to be used as biodiesel feedstock. Relatively higher extraction temperatures and longer extraction times tend to give parinari oil of reduced iodine values which may be more favourable for biodiesel production. However, longer residence times and extraction temperatures will have additional cost implications on the extraction process.

\section{Saponification value}

The statistical analysis indicated that the quadratic model equation Y4 was significant as shown by the "Prob > F" value which was less than 0.05 . The values of R2 and R2adj for Parinari oil extraction were obtained as 0.8729 and 0.8067 respectively, indicating the regression model having more than $80 \%$ acceptability. The probability plots of residuals obtained from parinari saponification value response data analysis is shown in Figure 2.

The main linear interaction effect was due to the coded terms A, B, C, D. The quadratic effect of time (A2) and the coded factors $\mathrm{A} 2, \mathrm{AB}, \mathrm{AC}, \mathrm{AD}, \mathrm{BD}$, and $\mathrm{CD}$ were also significant model terms. The insignificant terms $\mathrm{C}, \mathrm{BC}, \mathrm{C} 2$ and $\mathrm{D} 2$ were excluded from the model and the ANOVA summary obtained for the reduced response equation Y4 is shown in Table 5. The response model equation for saponification value in terms of coded factors is given in equation eq. 6 as:

$$
\begin{gathered}
252.69+0.53 \mathrm{~A}-1.2 \mathrm{~B}+0.38 \mathrm{C}+0.91 \mathrm{D}-5.08 A^{2}- \\
0.72 B^{2}-1.26 C^{2}+3.63 \mathrm{AB}-2.86 \mathrm{AC}-5.61 \mathrm{AD}+ \\
1.19 \mathrm{BC}-1.59 \mathrm{BD}+1.63 \mathrm{CD}
\end{gathered}
$$

Higher saponification values are indicative of the presence of lower molecular weight compounds/ short chain fatty acids in the oil. Higher saponification values are more desirable when considering oil for the soap industry. However, it is undesirable in the production of biodiesel. There is need to minimize the saponification value during extraction process of parinari oil that will be utilized for biodiesel production and the alcoholysis reaction stage of alkyd resin production.

For the interaction plots, Figure 7 illustrates the effect of extraction time on saponification value for the two different solvents. Saponification value increased gradually as extraction time increased in $\mathrm{n}$-hexane while saponification value decreased gradually as extraction time increased in petroleum ether. Relatively lower saponification values were obtained at shorter extraction time when $\mathrm{n}$-hexane solvent was used compared to that of petroleum ether. Higher saponification values suggest the presence of lower molecular weight molecules and breaking down of the oil triglyceride into lower molecular components at relatively higher temperature. The plot (Figure 7) indicates that extraction at lower temperatures favoured lower saponification values during the extraction of parinari oil when n-hexane was used. For the interaction plots, Figure 7 illustrates the effect of extraction time on saponification value for the two different solvents.

Saponification value increased gradually as extraction time increased in $n$-hexane while saponification value decreased gradually as extraction time increased in petroleum ether. Relatively lower saponification values were obtained at shorter extraction time when $\mathrm{n}$-hexane solvent was used compared to that of petroleum ether. Higher saponification values suggest the presence of lower molecular weight molecules and breaking down of the oil triglyceride into lower molecular components at relatively higher temperature. The plot (Figure 7) indicates that extraction at lower temperatures favoured lower saponification values during the extraction of parinari oil when n-hexane was used. This observation may indicate that prolonged heating time using petroleum ether may lead to certain polymerization reactions of the oil molecules of parinari, (having a relatively high iodine value) leading to lower saponification values and higher molecular weight.

\section{B. Extraction Process Optimization}

A standard approach (Uzoh et al., 2013) to the optimization exercise involves the formulation of global optimization criteria, considering necessary trade off in order to give an economically viable process with best oil properties within the design space. The global approach was adopted bearing in mind the optimization goals with concern for factors and responses that are indicative of minimal costs and maximal oil quality and profit (yield).

The optimization was achieved by setting the optimization goals as follows; minimize acid value, maximize iodine value, maximize oil yield, minimize temperature, minimize time maximize solid/solvent ratio within the design space. Since no unique solution was obtained, the optimal solution selected out of the 18 available options was based on economic considerations (Uzoh et al., 2013) that is, reduced temperature and time corresponds to reduced operating costs of the extraction process and the desirable oil characteristics. Table 6 shows the optimum values of process parameters obtained for corresponding optimal quality of parinari oil. The yield of 54\% which corresponds to optimal quality was relatively lower than $64.04 \%$ obtained without consideration for optimum quality characteristics (Afolabi et al., 2014).

The desirability of the optimization solution was 0.897 , indicating about $90 \%$ acceptability limits considering favorable independent variables; lower extraction times, lower extraction temperatures. Further validation experiments conducted at the predicted optimal conditions were in reasonable agreement with the predicted optimal values. Parinari oil has a relatively high iodine value and the oil can be conveniently classified as a drying oil comparable with linseed oil. High iodine value and refractive index are 
Table 5: Analysis of Variance (ANOVA) table for Parinari oil saponification value response surface reduced quadratic model $\mathrm{Y}_{4}$.

\begin{tabular}{llccll}
\hline Source & $\begin{array}{c}\text { Sum of } \\
\text { Squares }\end{array}$ & $\begin{array}{c}\text { Degree of } \\
\text { Freedom }\end{array}$ & $\begin{array}{c}\text { Mean } \\
\text { Square }\end{array}$ & F Value & Prob > F \\
\hline Model & 1909.12 & 13 & 146.86 & 13.20 & $<0.0001$ significant \\
Residual & 278.09 & 25 & 11.12 & & \\
Total & 2187.21 & 38 & & & \\
A & 6.54 & 1 & 0.59 & 6.54 & 0.4503 \\
B & 39.07 & 1 & 3.51 & 39.07 & 0.0726 \\
C & 4.04 & 1 & 4.04 & 0.36 & 0.5524 \\
D & 31.46 & 1 & 31.46 & 2.83 & 0.1051 \\
A $^{2}$ & 14.51 & 1 & 14.51 & 1.30 & 0.2642 \\
B & 46.30 & 1 & 46.30 & 4.07 & 0.0544 \\
AB & 211.07 & 1 & 211.07 & 18.97 & 0.0002 \\
AC & 130.91 & 1 & 130.91 & 11.77 & 0.0021 \\
AD & 728.11 & 1 & 728.11 & 65.46 & 0.0001 \\
BC & 22.83 & 1 & 22.83 & 2.05 & 0.1643 \\
BD & 69.43 & 1 & 69.43 & 6.24 & 0.0194 \\
CD & 72.60 & 1 & 72.60 & 6.53 & 0.0171 \\
Lack of Fit & 182.72 & 15 & 12.18 & 1.28 & 0.3548 \\
Pure Error & 95.38 & 10 & 9.54 & & \\
Std. Dev. & 3.34 & & R-Squared & 0.8729 & \\
Mean & 248.31 & & Adj R-Squared & 0.8067 & \\
C.V. & 1.34 & & Pred R-Squared & 0.6379 & \\
PRESS & 792.06 & Adeq Precision & 14.606 & \\
\hline
\end{tabular}

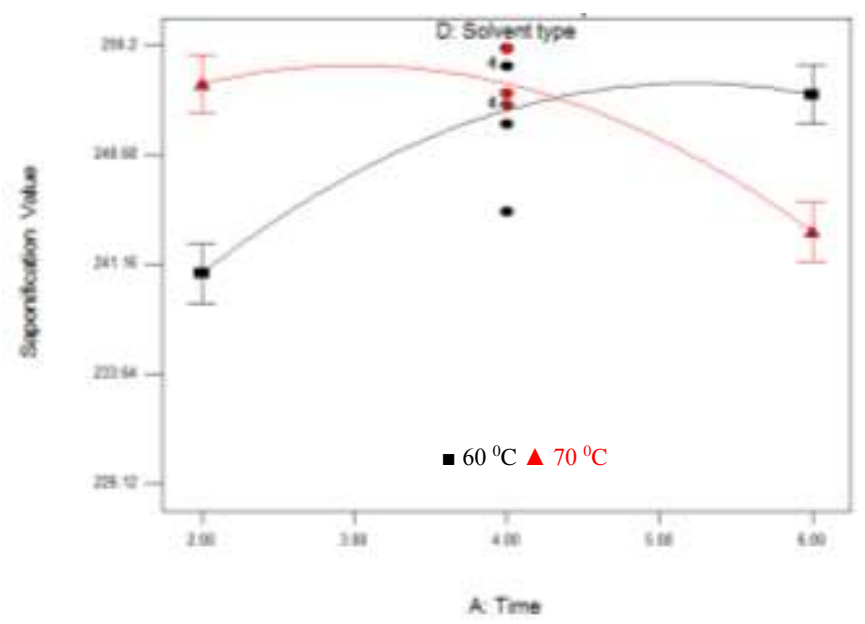

Figure 7: Saponification value interaction of solvent type with time.
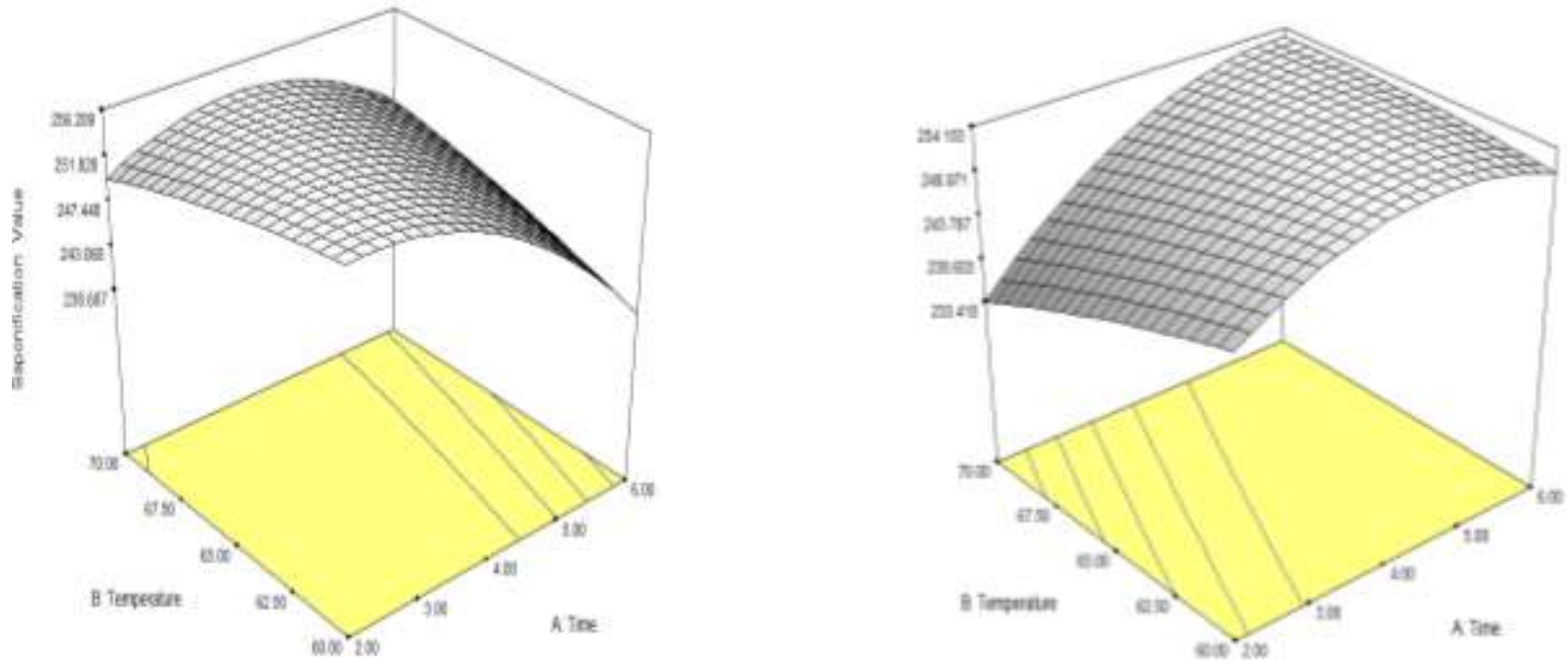

Figure 8: 3D response surface plots showing effect of temperature and time on iodine value for petroleum ether and n-hexane solvent type. 
indicative of high level of unsaturation in oil. Drying oils are raw materials for the oleochemical industry.

\section{CONCLUSION}

Extraction parameters were found to have varying effects on the acid, iodine and saponification values of the parinari oil. However, the solvent type did not have appreciable effect on the acid value of parinari oil. The temperature of extraction had the most significant effect on acid and iodine values while the extraction time had the most significant effect on the saponification value of parinari oil extraction process. Also, the optimum conditions for desirable quality of oil were obtained as an extraction time of 2 hours and an extraction temperature of 60 OC. Further work should be done on the effect of extraction parameters on the oil quality characteristics of parinari oil using other extraction methods.

\section{ACKNOWLEDGEMENTS}

The funding support provided through L'OrealUNESCO FWIS SSA Award 2014 is gratefully acknowledged.

\section{REFERENCES}

Abolaji O.A., Adebayo A.H. and Odesanmi O.S. (2007). Nutritional qualities of three medicinal plant parts (Xylopia aethiopica, Blighia sapida and Parinari polyandra) commonly used by pregnant women in the Western part of Nigeria. Pakistan Journal of Nutrition. 6 (6): 665-668.

Adewoye T.L. and Ogunleye, O.O. (2013). Optimization of neem seed oil extraction process using response surface methodology, Journal of Natural Science Research, 2012; 2(6):66-75.

Afolabi, T.J., Onifade K.R., Akindipe V.O. and Odetoye T.E. (2004). Optimization of solvent extraction of Parinari polyandra Benth seed oil using response surface methodology, British Journal of Applied Science \& Technology, 5 (5): 436-446.

Akowuah J.O., Addo A. and Kemausuor F. (2012). Influence of storage duration of Jatropha curcas seed on oil yield and free fatty acid content, ARPN Journal of Agricultural and Biological Science.; 7(1): 41-45.

AOAC (2006). Official Method of Analysis of AOAC International 18th edition. American Oil Chemists' Society Press: Champaign, IL.;

Firestone D. (2004). Official methods and recommended practices of the American Oil Chemists' Society. 5th ed. Champaign, Ill: AOCS (Method Cd 1-25, Cd 8-53 and Ca 5a40); 2004.

Giovacchino L.D., Soinas M. and Miccoll M. (1994). Effect of extraction systems on the quality of virgin olive oil, Journal of American Oil Chemists' Society, 71(11): 11891194.

Ikya J.K., Umenger L.N. and Iorbee A. (2013). Effects of Extraction Methods on the Yield and Quality Characteristics of Oils from Shea Nut. Journal of Food Resource Science. 2: $1-12$.

Islam M.N., Sabur A., Ahmmed R. and Hoque M.E. (2015). Oil Extraction from Pine Seed (Polyalthia longifolia) by Solvent Extraction Method and its Property Analysis Procedia Engineering 105:613.

Keay RWJ. (1989). Trees of Nigeria, Claredon Press; Oxford, 184-186.

Lee M.H., Kim S.S., Cho C.W., Choi S.Y., In G. and Kim K.T. (2014). Quality and characteristics of ginseng seed oil treated using different extraction methods, Journal of Ginseng Research, 37(4): 468-474.

Liauw M.Y., Natan F. A., Widiyanti P., Ikasari D., Indraswati N. and Soetaredjo F.E. (2013). Extraction of Neem Oil (Azadirachta indica A. Juss) Using N-Hexane and Ethanol: Studies of Oil Quality, Kinetic and Thermodynamic, ISSN ARPN Journal of Engineering and Applied Sciences, 3 (3).

Motojesi O., Ogunlaja A.S. and Amos, O. (2011). Variation in lipid composition of the seed oil of Parinari polyandra Benth, Asian Journal of Applied Sciences. 4(2) 195 $-201$.

Murphy D.J. (2012). The status of industrial vegetable oils from genetically modified plants, European Chemicals Agency report, 1-42.

Myung-Hee L, Sung-Soo K, Chang-Won C, SangYoon C, Gyo I, and Kyung-Tack K. (2013). Quality and characteristics of ginseng seed oil treated using different extraction methods, Journal of Ginseng Research. 37(4): 468474 .

Ngando-Ebongue G.F., Mpondo-Mpondo E.A., and Ewane M.A. Some quality parameters of crude palm oil from major markets of Douala, Cameroon. African Journal of Food Science 7(12): 473-478.

Odetoye T.E., Ogunniyi D.S. and Olatunji G.A. (2013). Studies on the preparation of Parinari polyandra Benth seed oil alkyd resins. Journal of Applied Polymer. Science, 127(6) 4610 - 4616.

Odetoye T.E., Ogunniyi D.S. and Olatunji G.A. (2014). Refining and characterization of underutilized seed oil of Parinari polyandra Benth for industrial utilization, Nigeria Journal of Pure and Applied Sciences. 27: 2538 - 2551.

Ogunniyi D.S. (2006). Castor oil a vital industrial raw material, Bioresource Technology (97) 1086-1089.

Orji M.U. and Mbata T.I. (2008). Effect of extraction methods on the quality and spoilage of Nigerian palm oil, African Journal of Biochemistry Research. 2 (9):192-196.

Samuagam L., Sia C.M., Akowuah G.A., Okechukwu P.N. and Yim H.S. (2013). The Effect of Extraction Conditions on Total Phenolic Content and Free Radical Scavenging Capacity of Selected Tropical Fruits' Peel, Health and the Environment Journal. 4, (2): 80-102.

Sereviratne K.N. and Dissanayake D.M. (2005). Effect of method of extraction on the quality of coconut oil, Journal of Science for University of Kelaniya. 2: 63-72

Taribak C., Casas L., Mantell C., Elfadli Z., Metni R. E., and Martínez de la Ossa E.J. (2013). Quality of Cosmetic Argan Oil Extracted by Supercritical Fluid Extraction from Argania spinosa L. Journal of Chemistry. Article ID 408194, 9 pages. http://dx.doi.org/10.1155/2013/408194.

Tasan M., Gecgel U. and Demirci M. (2011). Effects of storage and industrial oilseed extraction methods on the quality 
and stability characteristics of crude sunflower oil (Helianthus annuus L.), Grasas Y Aceites, 62 (4): 389-398.

Uzoh C.F., Onukwuli O.D., Odera R.S. and Ofochebe S. (2013). Optimization of polyesterification process for production of palm oil modified alkyd resin using response surface methodology, Journal of Environmental Chemical Engineering 2013;1:777 - 785 .

Zielińska A., Nowak I. and Mickiewicz A. (2014). Fatty acids in vegetable oils and their importance in cosmetic industry, CHEMIK; 68 (2): 103-110. 